\title{
The impact of Host vs. Graft mismatches on rejection of haploidentical bone marrow transplants in thalassemia patients using posttransplant cyclophosphamide
}

\author{
Priya Marwah ${ }^{1} \cdot$ Rajpreet Soni ${ }^{1} \cdot$ Stalin Ramprakash $\mathbb{1}^{2} \cdot$ C. P. Raghuram ${ }^{2} \cdot$ Deepa Trivedi $^{3}$. \\ Rajat Kumar Agarwal $\mathbb{D}^{4} \cdot$ Rakesh Dhanya $^{4} \cdot$ Amit Sedai $^{4} \cdot$ Ankita Kumari $^{4} \cdot$ Lalith Parmar $^{4} \cdot$ Lawrence Faulkner $^{5}$
}

Received: 6 January 2019 / Revised: 15 June 2019 / Accepted: 3 August 2019 / Published online: 30 September 2019

(c) The Author(s) 2019. This article is published with open access

\section{To the Editor:}

Blood or marrow transplantation can cure patients with transfusion-dependent thalassemia (TDT) [1] and normalize their long-term health-related quality of life [2]. In regions where TDT is most prevalent, $38-60 \%$ of transplant candidates may find a fully matched-related donor [3], thus a substantial proportion of patients require alternative donors. The use of posttransplant cyclophosphamide (PTCy) as well as ex vivo T-cell depletion methods have allowed to safely perform transplants across HLA barriers [4-6]. Because of its simplicity and inexpensiveness, PTCy seems a particularly attractive option for centers in lowermiddle-income countries (LMIC) in South-East Asia where TDT is the most frequent life-threatening noncommunicable disorder of childhood and a major financial burden to families and health care systems [7]. Outcomes using partially matched-related donors (PMRD) with the PTCy approach have been shown to be comparable with those using unrelated or related fully matched donors $[5,8]$, but unrelated donors in LMIC are often unavailable and/or unaffordable. In the PMRD transplantation context the

Supplementary information The online version of this article (https:// doi.org/10.1038/s41409-019-0692-0) contains supplementary material, which is available to authorized users.

Lawrence Faulkner

lawrence.faulkner@cure2children.org

1 South East Asia Institute for Thalassemia, Jaipur, India

2 People Tree Hospitals, Bangalore, India

3 Care Institute for Medical Sciences, Ahmedabad, India

4 Sankalp India Foundation, Bangalore, India

5 Cure2Children Foundation, Florence, Italy relevance of donor-specific antibodies (DSA) is well established [9], less so that of different degrees and types of HLA mismatches which, in fact, are not generally considered relevant [10].

We retrospectively assessed the impact of DSA as well as that of Host vs. Graft (HVG) set ups, i.e., when the recipient is homozygous for one or more HLA specificities while the donor is not, so that for those HLA specificities the recipient has the potential to react towards the unshared allele of the donor but not vice versa. A total of 28 consecutive partially matched-related BMTs where analyzed, these were performed between March 2017 and December 2018 in three centers in India: The South-East Asia Institute for Thalassemia in Jaipur, Rajasthan (20 cases), the People Tree Hospitals in Bangalore, Karnataka (seven cases), and the Care Institute for Medical Sciences in Ahmedabad (one case). Selection criteria included a diagnosis of TDT, lack of a fully matched-related donor, age at BMT $<15$ years (range $1.5-13.5$ years, median $5.3)$, no significant hepatosplenomegaly $(<2 \mathrm{~cm}$ from costal margin) or serum ferritin $>5000 \mathrm{ng} / \mathrm{mL}$ pre-BMT. None of the patients underwent a liver biopsy and thus would be considered Pesaro class I-II given the absence of hepatomegaly [1]. A common online electronic medical record system and collaboration platform where data were entered prospectively on a daily basis (BMTPlus , Jagrity Innovations, Bangalore, India, www.bmtplus.net) [11], and a single transplant approach approved by centers' IRB was used. The preparative regime, modified from Anurathapan at al. [5], is outlined in Supplementary Fig. 1. All caretakers provided informed consent to share personal data as well as for the BMT procedure. All patients received G-CSF-primed $(5 \mu \mathrm{g} / \mathrm{kg}$ twice daily from day -5 to -1 ) bone marrow with a total nucleated cell dose ranging from 12.1 to $52.9 \times 10^{8} /$ recipient $\mathrm{kg}$ (median 16.3). Post-BMT all blood products were 
irradiated with $\geq 25 \mathrm{~Gy}$. Autologous marrow was cryopreserved in all cases. Chimerism was monitored at least at 1,2,4, and 8 months by molecular (STR) analysis or Y chromosome cytogenetics or fluorescent in-situ hybridization when informative. All patients and immediate family members were HLA-typed by sequence-based high-resolution typing confirmed in two independent samples in different laboratories. All but one patient were evaluated for DSA status.

Data were collected and analyzed on 31 May 2019. Fisher's exact tests were used to compare proportions and Mann-Whitney nonparametric test were used to compare continuous distribution values. Kaplan-Meier survival curves were compared using the log-rank (Mantel-Cox) test. All $P$ values are two-tailed. Statistical analysis was performed using GraphPad Prism version 5.00 for Windows, GraphPad Software, San Diego, California, USA, www.graphpad.com.

Six out of twenty-five patients (24\%) had a rejection, with no significant differences in terms of sex, maternal vs. paternal donor, or cell dose between patient who rejected and those who did not (see Table 1). A total of 4 patients out of 27 evaluated for DSA where positive with mean fluorescent intensity $>2000,2 / 6$ in the rejection group (33\%) and $2 / 21$ in the nonrejection one (9\%). In the rejection group $3 / 6(50 \%)$ had a HVG set up (patient characteristics are summarized in Table 2). Actuarial rejection proportion went from $5 \%$ in patients with neither DSA-positivity nor HVG set up, to $56 \%$ in those with either one, see Supplementary Fig. 2. There was no overlap between DSA-positive patients and those with HVG set up. Among patients who did not reject $4 / 22$ (18\%) had a HVG set up, all with unilateral homozygosities at the A locus, in 2 the donor was DRB1 and DQB 1 compatible, in 1 was also B and C compatible, and in 1 was DRB1 and DQB1 unilaterally homozygous, thus there was a concomitant HVG and GHV set up. Both DSA-positive patients who did not reject had a GVH set up. None of the patients who rejected had a GVH set up. Of the 21 thalassemia-free patients, $18(86 \%)$ have $>95 \%$ donor chimerism, 2/22 (9\%) of engrafted patients developed grade III or IV GHVD, no case of extensive chronic GHVD has been observed so far. One patient died of grade IV GVHD and had a GVH set up, otherwise there was no apparent correlation between GVH set up and actual occurrence of GVHD. At a median follow up of 13 months (range 5.7-26.4) transplant-related mortality was $24 \%$ vs. $17 \%$ in $\mathrm{DSA}^{+} \mathrm{HVG}^{+}$and $\mathrm{DSA}^{-} \mathrm{HVG}^{-}$ patients respectively with a $P$ value of 0.53 .

Thalassemia seems an ideal model to study the role of immunogenetic factors in the HVG direction because of its
Table 1 Data summary of patients who rejected vs. those who did not

\begin{tabular}{|c|c|c|c|}
\hline & $\begin{array}{l}\text { Patients who } \\
\text { rejected }\end{array}$ & $\begin{array}{l}\text { Patients who did } \\
\text { not reject }\end{array}$ & $P$ \\
\hline Total patients & 6 & 22 & \\
\hline $\begin{array}{l}\text { Median age } \\
\text { (range) }\end{array}$ & $6.5(3.4-10)$ & $4.4(1.5-13.5)$ & 0.40 \\
\hline Sex & 4 males, 2 females & 16 males, 6 females & 1 \\
\hline Donor & 5 mother, 1 father & 13 mother, 6 father & 1 \\
\hline $\begin{array}{l}\text { Marrow cell } \\
\text { dose } \times 10^{8} / \mathrm{kg}\end{array}$ & $17.3(16-21.2)$ & $16.2(12.1-52.9)$ & 0.52 \\
\hline $\begin{array}{l}\text { Marrow white } \\
\text { cell count } / \mu \mathrm{L}\end{array}$ & $\begin{array}{l}55,445 \\
(31,730-75,600\end{array}$ & $\begin{array}{l}68,215 \\
(34,790-252,100)\end{array}$ & 0.15 \\
\hline
\end{tabular}

homogeneity, functional immune system and exposure to multiple transfusions resulting in higher potential for rejection compared with the hematological malignancy context. The observation that HLA HVG disparities can affect rejection in thalassemia patients has been previously reported in the unrelated setting [12] but not in the haploidentical-related one. A factor which might have contributed to not having identified this HLA vector effect previously in haploidentical BMT is that high-resolution typing is not routinely employed for related donor identification [13], while high-resolution mismatches may have the same clinical significance as low-resolution ones [14]. In fact, the identification of a HLA vector is based on the assumption of true homozygosity of one or more HLA alleles.

We believe that even if PTCy is quite effective in inducing tolerance, some degree of escape still remains since GHVD is not infrequent albeit generally mild and manageable. The same maybe true in the HVG (rejection) direction.

In conclusion, these findings may have important practical implications for the selection of partially matched donors for nonmalignant conditions in which rejection is a potential issue. With all the limitations of a small case series, in our experience the presence of a HVG set up in the context of thalassemia seems as impactful on rejection as that of DSA. The potential implication is that in this context it might be advisable to get high-resolution HLA typing and possibly consider the use of unrelated donors in the presence of unilateral recipient's HLA homozygosities. This occurrence maybe more frequent in populations with high consanguinity or close ethnicity, like in the Indian subcontinent. The impact of HLA vectors in the HVG or GVH direction in haploidentical transplantation for thalassemia may deserve to be assessed in larger studies. 


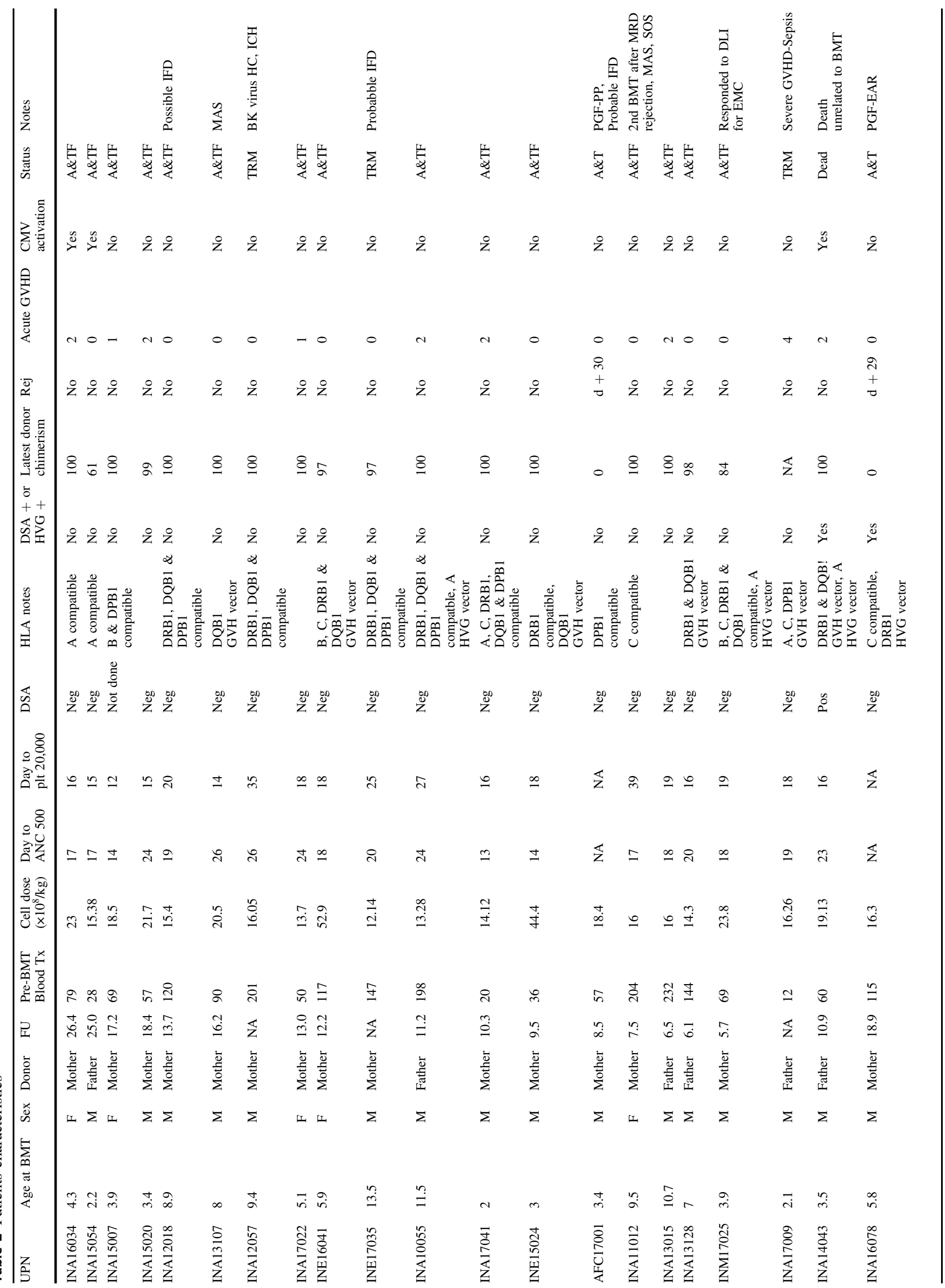


Acknowledgements The authors thank the patients, their parents, and all the nurses and physicians at collaborating institutions. This work was partially supported by Sankalp India Foundation, Bangalore, India, Cure2Children Foundation, Florence, Italy, and Fondazione Umberto Veronesi, Milan, Italy. We are also grateful to DKMS, Tübingen, Germany for providing free HLA typing.

\section{Compliance with ethical standards}

Conflict of interest The authors declare that they have no conflict of interest.

Publisher's note Springer Nature remains neutral with regard to jurisdictional claims in published maps and institutional affiliations.

Open Access This article is licensed under a Creative Commons Attribution 4.0 International License, which permits use, sharing, adaptation, distribution and reproduction in any medium or format, as long as you give appropriate credit to the original author(s) and the source, provide a link to the Creative Commons license, and indicate if changes were made. The images or other third party material in this article are included in the article's Creative Commons license, unless indicated otherwise in a credit line to the material. If material is not included in the article's Creative Commons license and your intended use is not permitted by statutory regulation or exceeds the permitted use, you will need to obtain permission directly from the copyright holder. To view a copy of this license, visit http://creativecommons. org/licenses/by/4.0/.

\section{References}

1. Lucarelli G, Galimberti M, Polchi P, Angelucci E, Baronciani D, Giardini $\mathrm{C}$, et al. Bone marrow transplantation in patients with thalassemia. N Engl J Med. 1990;322:417-21.

2. La Nasa G, Caocci G, Efficace F, Dessì C, Vacca A, Piras E, et al. Long-term health-related quality of life evaluated more than 20 years after hematopoietic stem cell transplantation for thalassemia. Blood. 2013;122:2262-70.

3. Agarwal RK, Kumari A, Sedai A, Parmar L, Dhanya R, Faulkner L. The case for high resolution extended 6-Loci HLA typing for identifying related donors in the Indian subcontinent. Biol Blood Marrow Transpl. 2017;23:1592-6.

4. Sodani P, Isgro A, Gaziev J, Polchi P, Paciaroni K, Marziali M, et al. Purified T-depleted, CD34+ peripheral blood and bone marrow cell transplantation from haploidentical mother to child with thalassemia. Blood. 2010;115:1296-302.

5. Anurathapan U, Hongeng S, Pakakasama S, Sirachainan N, Songdej D, Chuansumrit A, et al. Hematopoietic stem cell transplantation for homozygous $\beta$-thalassemia and $\beta$-thalassemia/ hemoglobin E patients from haploidentical donors. Bone Marrow Transpl. 2016;51:813-8.

6. Gaziev J, Isgrò A, Sodani P, Paciaroni K, Angelis GD, Marziali M, et al. Haploidentical HSCT for hemoglobinopathies: improved outcomes with TCR $\alpha \beta+/ C D 19+-$ depleted grafts. Blood Adv. 2018;2:263-70.

7. Modell B, Darlison M. Global epidemiology of haemoglobin disorders and derived service indicators. Bull World Health Organ. 2008;86:480-7.

8. Martínez C, Gayoso J, Canals C, Finel H, Peggs K, Dominietto A, et al. Post-transplantation cyclophosphamide-based haploidentical transplantation as alternative to matched sibling or unrelated donor transplantation for hodgkin lymphoma: a 
registry study of the lymphoma working party of the European Society for Blood and Marrow Transplantation. J Clin Oncol. 2017;35:3425-32.

9. Ciurea SO, Cao K, Fernadez-Vina M, Kongtim P, Malki MA, Fuchs E, et al. The European Society for Blood and Marrow Transplantation (EBMT) consensus guidelines for the detection and treatment of donor-specific anti-HLA antibodies (DSA) in haploidentical hematopoietic cell transplantation. Bone Marrow Transpl. 2018;53:521-34.

10. Raiola AM, Risitano A, Sacchi N, Giannoni L, Signori A, Aquino $S$, et al. Impact of HLA disparity in haploidentical bone marrow transplantation followed by high-dose cyclophosphamide. Biol Blood Marrow Transplant. 2018;24:119-26.

11. Agarwal RK, Sedai A, Dhimal S, Ankita K, Clemente L, Siddique $\mathrm{S}$, et al. A prospective international cooperative information technology platform built using open-source tools for improving the access to and safety of bone marrow transplantation in low- and middle-income countries. $\mathrm{J}$ Am Med Inf Assoc. 2014;21:1125-8.

12. Fleischhauer K, Locatelli F, Zecca M, Orofino MG, Giardini C, De Stefano $\mathrm{P}$, et al. Graft rejection after unrelated donor hematopoietic stem cell transplantation for thalassemia is associated with nonpermissive HLA-DPB1 disparity in host-versus-graft direction. Blood. 2006;107:2984-92.

13. Howard CA, Fernandez-Vina MA, Appelbaum FR, Confer DL, Devine SM, Horowitz MM, et al. Recommendations for donor human leukocyte antigen assessment and matching for allogeneic stem cell transplantation: consensus opinion of the Blood and Marrow Transplant Clinical Trials Network (BMT CTN). Biol Blood Marrow Transplant. 2015;21:4-7.

14. Eapen M, Klein JP, Ruggeri A, Spellman S, Lee SJ, Anasetti C, et al. Impact of allele-level HLA matching on outcomes after myeloablative single unit umbilical cord blood transplantation for hematologic malignancy. Blood. 2014;123:133-40. 